\title{
Flora das cangas da Serra dos Carajás, Pará, Brasil: Opiliaceae
}

\author{
Flora of the cangas of Serra dos Carajás, Pará, Brazil: Opiliaceae
}

Aline Joseph Ramalho ${ }^{1,2,4} \&$ Daniela Cristina Zappi ${ }^{1,3}$

\begin{abstract}
Resumo
O presente estudo apresenta o tratamento taxonômico de Opiliaceae para as formações de canga da Serra dos Carajás (Pará, Brasil), onde foi registrada apenas uma espécie, Agonandra silvatica Ducke, táxon de distribuição Neotropical (Guianas, Equador, Peru, Brasil e Norte da Bolivia). São apresentadas descrição detalhada, comentários e fotografias em campo da espécie.
\end{abstract}

Palavras-chave: Agonandra silvatica, canga, FLONA Carajás, Santalales, taxonomia.

\begin{abstract}
This study presents the taxonomic treatment of Opiliaceae for the canga formations of Serra dos Carajás (Pará state, Brazil), where only one species was recorded, Agonandra silvatica Ducke, a taxon of Neotropical distribution (The Guianas, Ecuador, Peru, Brazil, and Northern Bolivia). Detailed description, comments and photos in the field of the species are presented.
\end{abstract}

Key words: Agonandra silvatica, canga, FLONA Carajás, Santalales, taxonomy.

\section{Opiliaceae}

Opiliaceae Valeton é uma pequena família pantropical com centros de diversidade no Sudeste da Ásia e Oceania (Hiepko 2000; Marquete 2010). Compreende 10 gêneros e 33 espécies (Hiepko 2000) de arbustos e árvores, raramente trepadeiras; caracterizadas por folhas alternas, simples e de margem inteira, pecioladas e sem estípulas; inflorescências axilares ou caulifloras, raramente terminais, cimosas ou racemosas; flores pouco vistosas, bissexuadas ou unissexuadas, actinomórficas; cálice muito reduzido, 4-5-mero, prefloração aberta; corola 4-5-mera; estames em número igual ao das pétalas e opostos a elas, frequentemente epipétalos; anteras rimosas; ovário súpero, 2-5-carpelar, unilocular, uniovulado, placentação pêndula ou, unicamente em Agonandra, basal; fruto drupáceo (Hiepko 2000; Elias et al. 2002; Souza \& Lorenzi 2012).

No Brasil, Opiliaceae está representada apenas pelo gênero Agonandra Miers ex Benth. \& Hook.f. com distribuição em todos os estados do país exceto no Rio Grande do Norte, Paraíba, Alagoas e Sergipe (BFG 2015). Nas cangas da Serra dos Carajás, apenas o gênero Agonandra foi registrado.

\section{Agonandra Miers ex Benth. \& Hook.f.}

Agonandra é caracterizado por serem plantas dioicas com folhas glabras, inflorescência racemosa com 1-3(-4) flores por bráctea, bráctea geralmente peltada, caduca; raque glabra, papilada ou pubescente. Flores verdes, amarelo-esverdeadas ou brancas, pediceladas ou sésseis, tépalas livres. Na flor masculina, o pistilódio é rudimentar enquanto que na flor feminina, que é desprovida de estames, o disco apresenta-se anular e muito pequeno e o pistilo tem estigma séssil. Drupa elipsoide, às vezes globosa, pedicelo cilíndrico ou distalmente alargado (Hiepko 2000).

Agonandra é o único gênero neotropical da família, contando com 10 espécies distribuídas desde o México até o norte da Argentina. No Brasil ocorrem cinco espécies e uma subespécie em todos os domínios fitogeográficos, com exceção dos Pampas (BFG 2015). Apenas uma espécie, Agonandra silvatica Ducke, foi registrada nas cangas da Serra dos Carajás.

1.1. Agonandra silvatica Ducke, Arch. Jard. Bot. Rio de Janeiro 3:41. 1922.

Fig. 1a-b

Árvores ou arbustos, $2-7 \mathrm{~m}$ alt., ramos jovens glabros. Folhas $(2,7-) 4,6-7,9 \times(1,2-) 2-3,7 \mathrm{~cm}$,

\footnotetext{
'Instituto Tecnológico Vale, R. Boaventura da Silva 955, Nazaré, 66055-090, Belém, PA, Brasil.

${ }^{2}$ Museu Paraense Emílio Goeldi, Campus de Pesquisa, Coord. Botânica, Prog. Capacitação Institucional, Av. Perimetral 1901, Terra Firme, 66077-830, Belém, PA, Brasil.

${ }^{3}$ Museu Paraense Emílio Goeldi, Campus de Pesquisa, Coord. Botânica, Av. Perimetral 1901, Terra Firme, 66077-830, Belém, PA, Brasil.

${ }^{4}$ Autor para correspondência: alinejr@gmail.com
} 

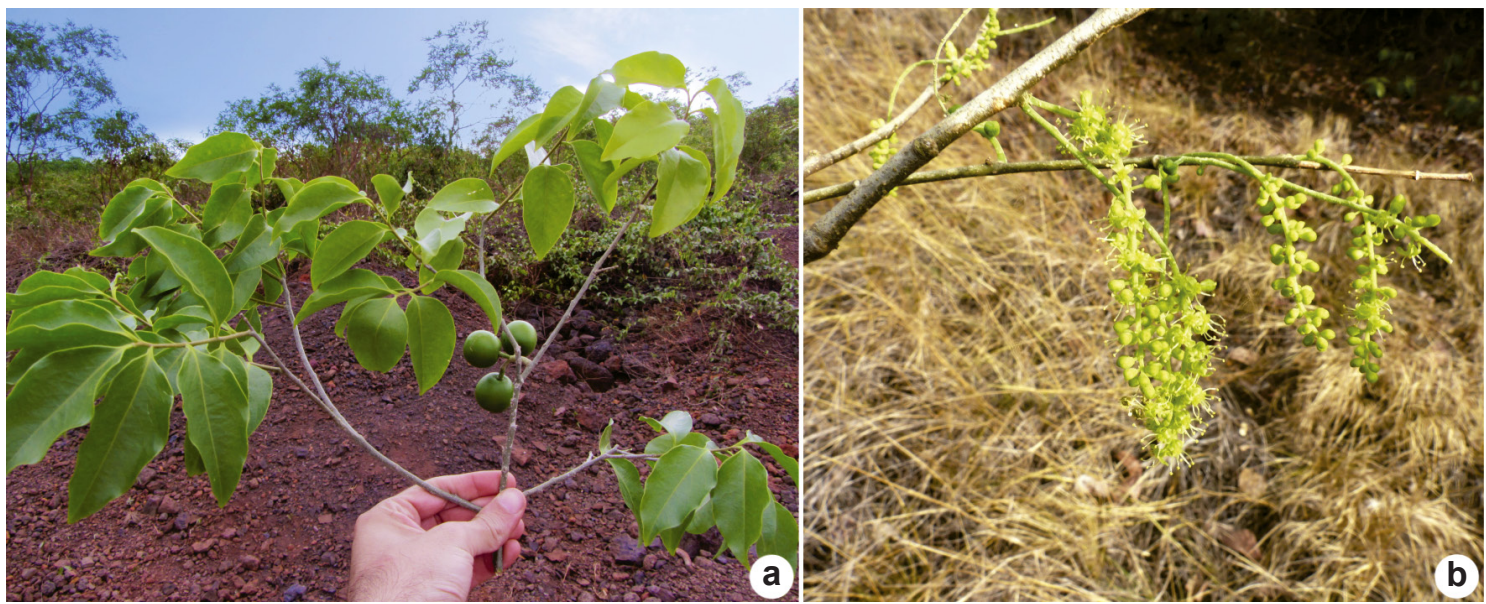

Figura 1 - a-b. Agonandra silvatica - a. ramo da planta com frutos; b. flores masculinas. Fotos: a. L.V. Vasconcelos, b. R.M. Harley.

Figure 1 - a-b. Agonandra silvatica - a. fruiting branch; b. male flowers. Photos: a. L.V. Vasconcelos, b. R.M. Harley.

pecíolo 3,7-5,9(-7,2) mm compr., ovadas a elípticas, ápice agudo a acuminado base atenuada, cartáceas a coriáceas, nervuras indistintas. Racemos axilares, 1-4 por axila, raque 1,8$2,6(-4,6) \mathrm{cm}$ compr., papilosa-glandulosa. Flores masculinas geralmente 3 por bráctea, papilosas; brácteas ovadas com margem ciliada, decídua; pedicelo $1-1,7 \mathrm{~mm}$ compr., papiloso; tépalas oblongas, agudas, 1,5-2 × 0,8-1 mm; estames 2,3$3 \mathrm{~mm}$ compr., antera sulcada ápice arrendondado; lóbulos do disco isolados, denteados; pistilo rudimentar estreitamente cilíndrico $0,5-0,7 \mathrm{~mm}$ compr. Flores femininas geralmente 3 por bráctea, papilosas; bráctea fortemente côncava, oblonga e aguda no ápice, com margem serrilhada, decídua; pedicelo 4,6-7,6(-10,6) $\mathrm{mm}$ compr.; tépalas oblongas, agudas, $0,8-1,1 \times 0,3-0,7 \mathrm{~mm}$; pistilo globoso. Drupas globosas.

Material selecionado: Canaã dos Carajás, Serra Sul, S11A, Lagoa das Três Irmãs, 06 20 ' $51^{\prime}$ 'S, $50^{\circ} 26^{\prime} 03^{\prime \prime} \mathrm{W}, 724 \mathrm{~m}, 10 . \mathrm{VIII} .2016$, fl. e fr., R.M. Harley 57895 (MG). Parauapebas, Serra Norte, $\mathrm{N} 1,06^{\circ} 00^{\prime} 45^{\prime \prime} \mathrm{S}, 50^{\circ} 18^{\prime} 10^{\prime} \mathrm{W}, 753 \mathrm{~m}, 13 . \mathrm{X} .2008$, fl., L.V. Costa et al. 631 (BHCB); N7, 0609'20"'s, $50^{\circ} 10^{\prime} 27^{\prime}$ 'W, $686 \mathrm{~m}, 13$.VIII.2016, f1., L.V. Vasconcelos et al. 924 (MG).

Foram reconhecidos registros de duas espécies de Agonandra no estado do Pará: Agonandra brasiliensis Miers ex Benth. \& Hook.f., cuja distribuição estende-se até a Mata Atlântica, Cerrado e Caatinga, e A. silvatica no domínio da Amazônia (BFG 2015). Agonandra silvatica difere das outras espécies do gênero por apresentar papilas ao longo da raque da inflorescência, pecíolos e flores, e lóbulos do disco regularmente denteados. Em $A$. brasiliensis o indumento da raque, pecíolos e flores é pubescente e o ápice do disco é irregularmente denteado. A. peruviana Hiepko, única outra espécie da Amazônia brasileira, caracteriza-se por suas flores glabras com pedicelos mais longos do que $A$. silvatica e as flores masculinas com lóbulos do disco fundidos. Hiepko (2000) descreve A. silvatica como arbórea, atingindo $40 \mathrm{~m}$ alt., enquanto que na área de estudo foram observados indivíduos de até $7 \mathrm{~m}$ alt.

Agonandra silvatica de distribuição na América do Sul, ocorrendo nas Guianas, Equador, Peru e Bolívia. No Brasil foi registrada em todos os estados da região Norte, exceto em Roraima (BFG 2015). Na Serra dos Carajás: Serra Norte: N1, N7; Serra Sul: S11A. Foi coletada em flor em agosto e outubro e em fruto em outubro, em beira de capão de mata e proximidades de lagoas sobre canga.

\section{Agradecimentos}

Agradecemos ao Museu Paraense Emílio Goeldi e ao Instituto Tecnológico Vale, a estrutura e o apoio fundamentais ao desenvolvimento deste trabalho. Aos curadores dos herbários (BHCB, HCSJ, IAN e MG), a disponibilização dos materiais examinados. Ao projeto objeto do convênio MPEG/ITV/FADESP (01205.000250/2014-10) e ao projeto aprovado pelo $\mathrm{CNPq}$ (processo 455505/2014-4), o financiamento. 


\section{Referências}

BFG - The Brazil Flora Group (2015) Growing knowledge: an overview of seed plant diversity in Brazil. Rodriguésia 66: 1085-1113.

Elias SI, Souza VC \& Rodrigues RR (2002) Opiliaceae In: Wanderley MGL, Shepherd GJ, Giulietti AM, Melhem TS, Bittrich V \& Kameyama C (eds.) Flora Fanerogâmica do Estado de São Paulo. Instituto de Botânica, São Paulo. Vol. 2, pp. 219-222.

Hiepko P (2000) Opiliaceae. Flora Neotropica Monograph 82: 1-53.
Marquete R (2010) Neotropical Opiliaceae. In: Milliken W, Klitgård B \& Baracat A [2009 onwards] Neotropikey - Interactive key and information resources for flowering plants of the Neotropics. Disponível em <http://www.kew.org/science/ tropamerica/neotropikey/families/Opiliaceae. $\mathrm{htm}>$. Acesso em 6 fevereiro 2017.

Souza VC \& Lorenzi H (2012) Botânica Sistemática: guia ilustrado para identificação das famílias de Fanerógamas nativas e exóticas do Brasil, baseado em APG III. $3^{\text {a }}$ ed. Instituto Plantarum, Nova Odessa, São Paulo. 768p.

\section{Lista de exsicatas}

Costa LV 631 (1.1). Harley RM 57895 (1.1). Lobato LCB 4452 (1.1). Vasconcelos LV 924 (1.1), 1040 (1.1). Tyski L 18 (1.1). 